\title{
Synthesis and Structural Characterization of Block and Random Low Molecular Weight Copolymers Composed of L-lactic Acid and Isosorbide Succinate Moieties
}

\author{
Romeu Casarano, ${ }^{a}$ Denise F. S. Petri, ${ }^{a}$ Michael Jaffe ${ }^{b}$ and Luiz H. Catalani ${ }^{*, a}$ \\ ${ }^{a}$ Instituto de Química, Universidade de São Paulo, 05513-970 São Paulo-SP, Brazil \\ ${ }^{b}$ Medical Device Concept Laboratory, New Jersey Institute of Technology, Newark, USA
}

\begin{abstract}
Resíduos de succinato de isosorbídeo foram incorporados na cadeia principal de poli(L-lactídeo) (PLLA) visando a obtenção de uma nova classe de polímeros biodegradáveis com propriedades melhoradas. Este artigo descreve a síntese e caracterização de quatro tipos de copolímeros de baixa massa molar. O copolímero I foi obtido da mistura dos monômeros L-lactídeo, isosorbídeo e anidrido succínico; II do oligo(L-lactídeo) (PLLA), isosorbídeo e anidrido succínico; III do oligo(succinato de isosorbídeo) (PIS) e L-lactídeo; e IV de reações de transesterificação entre PLLA e PIS. Análises de MALDI-TOFMS e ${ }^{13} \mathrm{C}-\mathrm{NMR}$ apresentaram evidências de que cooligomerização foi alcançada em todos os casos. Os dados sugerem que o produto I é um cooligômero aleatório e que os produtos II-IV são cooligômeros em bloco.
\end{abstract}

Isosorbide succinate moieties were incorporated into poly(L-lactide) (PLLA) backbone in order to obtain a new class of biodegradable polymer with enhanced properties. This paper describes the synthesis and characterization of four types of low molecular weight copolymers. Copolymer I was obtained from monomer mixtures of L-lactide, isosorbide, and succinic anhydride; II from oligo(L-lactide) (PLLA), isosorbide, and succinic anhydride; III from oligo(isosorbide succinate) (PIS) and L-lactide; and IV from transesterification reactions between PLLA and PIS. MALDITOFMS and ${ }^{13} \mathrm{C}$-NMR analyses gave evidence that co-oligomerization was successfully attained in all cases. The data suggested that the product $\mathbf{I}$ is a random co-oligomer and the products II-IV are block co-oligomers.

Keywords: isosorbide, PLLA, PIS, copolymers, MALDI-TOF

\section{Introduction}

The use of biodegradable and biocompatible polymers in biomedical applications has been recognized as desirable, where their non-toxicity is of fundamental importance. ${ }^{1}$ The choice of polymers to be employed as biomaterial relies on the general criteria that their mechanical properties and biodegradation time have to be compatible with the application needs. ${ }^{2}$

Most of the biodegradable polymers contain hydrolysable linkages along the polymeric chain, such as polyesters like poly(L-lactide) or poly(L-lactic acid) (PLLA), depending on which starting material was used: L-lactide or L-lactic acid, poly (glycolic acid) (PGA), polycaprolactone (PCL), poly(trimethylene carbonate), and poly(3-hydroxybutyrate) (PHB). ${ }^{3}$ Poly (L-lactide) is obtained from L-lactide ( $(\mathrm{S}, \mathrm{S})$ -

\footnotetext{
*e-mail: catalani@usp.br
}

3,6-dimethyl-1,4-dioxane-2,5-dione), a cyclic diester of L-lactic acid, a naturally occurring isomer. ${ }^{2}$

A class of biodegradable and bioresorbable polyesters little explored is that derived from 1,4:3,6-dianhydrohexitols and alkyl diacids, e.g. poly(isosorbide succinate) (PIS). ${ }^{4}$ The 1,4:3,6-dianhydrohexitols, such as isosorbide (1,4:3,6-dianhydro-D-sorbitol or -D-glucitol), are important monomers in view of their non-toxicity and renewable origin. ${ }^{5,6}$ Likewise, succinic acid is produced from glucose by fermentation ${ }^{7}$ and is readily metabolized by the Krebs cycle.

The incorporation of isosorbide into polyesters backbone has proven to be an advantageous artifice to obtain products of enhanced properties. In special, the inclusion of small quantities of isosorbide into aromatic polyesters affords polymers with higher $\mathrm{T}_{\mathrm{g}}$, opening new windows of applications for these materials. ${ }^{8,9}$

Copolymers can be synthesized through various synthetic routes. Depending on the synthetic method 
employed one can obtain alternating, random, or block copolymer structures. ${ }^{10}$ On the other hand, most of the interest on step copolymerization lies on the production of block and random copolymer structures, whose properties can be close or very different to the weighted average of the corresponding homopolymers, respectively. ${ }^{10}$

Matrix-assisted laser desorption/ionization timeof-flight mass spectrometry (MALDI-TOFMS) has been used as a very powerful tool on homopolymer and copolymer characterization. From this technique, one can obtain information not only on average molar mass, molar mass distribution and end groups analysis, but also on polymerization mechanisms by analyzing the formation and the reactivity of functional groups as well as determining anomalous structures eventually formed as consequence of side reactions. ${ }^{11-17}$

In this work we investigated four different approaches for the synthesis of biodegradable aliphatic polyesters composed of L-lactic acid (LLA), isosorbide (I), and succinate (S) moieties using copolymerization techniques. SEC, MALDI-TOFMS, ${ }^{13} \mathrm{C}$ NMR spectrometry and WAXD were used to access their structural characterization.

\section{Experimental}

\section{Materials}

Isosorbide (Aldrich) and L-lactide (Aldrich) were recrystallized, respectively, twice and once from dry ethyl acetate $\left(\mathrm{mp}\right.$ 63.5-63.6 ${ }^{\circ} \mathrm{C}$ and $92.3-92.7^{\circ} \mathrm{C}$, respectively). Succinic anhydride (Aldrich) was refluxed with acetic anhydride for $10 \mathrm{~min}$, filtered, and then washed with cold dry ethyl ether ${ }^{18}$ (mp 121.0-121.1 ${ }^{\circ} \mathrm{C}$ ). Tin(II) 2-ethylhexanoate (Aldrich; $c a .95 \% ;$ SnOct $_{2}$ ) and $p$-toluenesulfonic acid (Aldrich; 98.5\%) were used as catalyst without further purification. Chloroform (Synth) and anhydrous methanol (Mallinckrodt) of analytical grade were used as received.

\section{Synthesis}

Two samples of PLLA were synthesized in bulk by ring-opening polymerization with different average molar masses. Synthesis of PLLA1 (higher average molar mass): L-lactide $\left(1.000 \mathrm{~g} ; 6.9 \times 10^{-3} \mathrm{~mol}\right)$ and $\mathrm{SnOct}_{2}(0.023 \mathrm{~g}$; $5.7 \times 10^{-5} \mathrm{~mol}$ ) were added to an assay tube, purged with $\mathrm{N}_{2}$, sealed, and kept in an oil bath at $120{ }^{\circ} \mathrm{C}$ for $35 \mathrm{~h}$. The same procedure was used for PLLA2 (lower average molar mass), except for the amount of $\mathrm{SnOct}_{2}(0.0010 \mathrm{~g}$; $\left.2.5 \times 10^{-6} \mathrm{~mol}\right)$. The reaction temperature was chosen based on literature data. ${ }^{19-21}$

PIS was synthesized by step polymerization through azeotropic distillation: isosorbide (14.6 g; $0.1 \mathrm{~mol})$, succinic anhydride ( $10.0 \mathrm{~g} ; 0.1 \mathrm{~mol}), p$-toluenesulfonic acid $(0.017 \mathrm{~g}$; $1 \times 10^{-4} \mathrm{~mol}$ ), and dry chloroform were added to a one-necked round-bottom flask of $250 \mathrm{~mL}$. The reaction was kept in reflux for $28 \mathrm{~h}$, using a modified Dean-Stark apparatus filled with previously dried molecular sieves of $3 \AA$.

Product $\mathbf{I}$ was synthesized by copolymerization techniques involving both ring-opening and step copolymerizations from L-lactide, isosorbide, succinic anhydride, and $\mathrm{SnOct}_{2}$; product II via step copolymerization from PLLA2, isosorbide, and succinic anhydride; product III by ring-opening copolymerization from PIS, L-lactide, and $\mathrm{SnOct}_{2}$; product IV from copolymerization via transesterification reactions between PLLA1 and PIS, in the presence of SnOct $_{2}$. The general procedure for the four bulk copolymerizations: all reagents were sealed in an assay tube after purging with $\mathrm{N}_{2}$ and heated in oil bath at different temperature and time. The copolymerization was carried out under reduced pressure only in the synthesis of the product I. Table 1 describes the quantities and conditions used for

Table 1. Quantities and conditions used for the syntheses of the products I-IV, as well as the corresponding yields

\begin{tabular}{|c|c|c|c|c|c|c|}
\hline Run & Reagent 1 & Reagent 2 & Reagent 3 & Reagent 4 & Conditions & Yield / (\%) \\
\hline$\overline{\mathbf{I}^{\mathrm{g}}}$ & $\begin{array}{c}\text { LLA }^{\mathrm{a}} \\
1.131 \mathrm{~g} ; \\
7.8 \times 10^{-3} \mathrm{~mol}\end{array}$ & $\begin{array}{c}\mathrm{SA}^{\mathrm{b}} \\
0.196 \mathrm{~g} ; \\
2.0 \times 10^{-3} \mathrm{~mol}\end{array}$ & $\begin{array}{c}\text { Isosorbide }^{\mathrm{c}} \\
0.286 \mathrm{~g} \\
2.0 \times 10^{-3} \mathrm{~mol}\end{array}$ & $\begin{array}{c}\text { SnOct }_{2}^{\mathrm{d}} \\
3 \mathrm{mg} ; \\
7.4 \times 10^{-6} \mathrm{~mol}\end{array}$ & $\begin{array}{c}150{ }^{\circ} \mathrm{C} \\
10 \mathrm{~h}-1 \mathrm{~atm} \\
24 \mathrm{~h}-1 \mathrm{mmHg}\end{array}$ & 43 \\
\hline $\mathbf{I I}^{\mathrm{g}}$ & $\begin{aligned} & \text { PLLA2 }^{\mathrm{f}} \\
& 0.406 \mathrm{~g} ; \\
\overline{\mathrm{M}}_{\mathrm{n}}= & 3.050 \mathrm{~g} \mathrm{~mol}^{-1}\end{aligned}$ & $\begin{array}{c}\mathrm{SA}^{\mathrm{b}} \\
0.075 \mathrm{~g} ; \\
7.5 \times 10^{-4} \mathrm{~mol}\end{array}$ & $\begin{array}{c}\text { Isosorbide }^{\mathrm{c}} \\
0.108 \mathrm{~g} \\
7.4 \times 10^{-4} \mathrm{~mol}\end{array}$ & - & $\begin{array}{c}150{ }^{\circ} \mathrm{C} \\
1 \mathrm{~atm} \\
32 \mathrm{~h}\end{array}$ & 40 \\
\hline IIII $^{\mathrm{g}}$ & $\begin{array}{c}\text { LLA }^{\mathrm{a}} \\
0.751 \mathrm{~g} ; \\
5.2 \times 10^{-3} \mathrm{~mol}\end{array}$ & $\begin{array}{c}\mathrm{PIS}^{\mathrm{e}} \\
0.322 \mathrm{~g} \\
\overline{\mathrm{M}}_{\mathrm{n}}=2.300 \mathrm{~g} \mathrm{~mol}^{-1}\end{array}$ & - & $\begin{array}{c}\mathrm{SnOct}_{2}^{\mathrm{d}} \\
10 \mathrm{mg} ; \\
2.5 \times 10^{-5} \mathrm{~mol}\end{array}$ & $\begin{array}{c}120^{\circ} \mathrm{C} \\
1 \mathrm{~atm} \\
36 \mathrm{~h}\end{array}$ & 52 \\
\hline$I^{g}$ & $\begin{array}{c}\text { PLLA } 1^{\mathrm{f}} \\
0.500 \mathrm{~g} ; \\
\overline{\mathrm{M}}_{\mathrm{n}}= \\
9.100 \mathrm{~g} \mathrm{~mol}^{-1}\end{array}$ & $\begin{array}{c}\text { PISe } \\
0.214 \mathrm{~g} \\
\overline{\mathrm{M}}_{\mathrm{n}}=2.300 \mathrm{~g} \mathrm{~mol}^{-1}\end{array}$ & - & $\begin{array}{c}\text { SnOct }_{2}^{\mathrm{d}} \\
0.9 \mathrm{mg} ; \\
2.2 \times 10^{-6} \mathrm{~mol}\end{array}$ & $\begin{array}{l}150{ }^{\circ} \mathrm{C} \\
1 \mathrm{~atm} \\
16.5 \mathrm{~h}\end{array}$ & 58 \\
\hline
\end{tabular}

${ }^{\mathrm{a}}$ L-lactide; ${ }^{\mathrm{b}}$ succinic anhydride; ${ }^{\mathrm{c}}$ 1,4:3,6-dianhydro-D-glucitol; ${ }^{\mathrm{d}}$ tin(II) 2-ethylhexanoate; ${ }^{\mathrm{o}}$ oligo(isosorbide succinate); ${ }^{\mathrm{f}}$ oligo(L-lactide) with different average molar masses; ${ }^{\mathrm{g}} \mathrm{oligo}(\mathrm{L}-$ lactide-co-isosorbide succinate); they contain the same monomer moieties, but were obtained from different ways. 
each experiment. The reaction temperature $\left(150{ }^{\circ} \mathrm{C}\right)$ for the syntheses of I and II was based on literature values for the production of PIS homopolymer in bulk. ${ }^{4}$ The same temperature was also used for the synthesis of IV to allow complete melting of the starting materials.

\section{Purification}

PLLA1, PLLA2, PIS, and the products I-IV were purified by dissolving in chloroform (1 volume), precipitating in methanol (10 volumes), and drying the filtrated in a vacuum-oven at $40^{\circ} \mathrm{C}$ for $48 \mathrm{~h}$, except PIS and product I, which were vacuum-dried at RT. Table 1 also gives the corresponding yields of these four products. The yields obtained for PLLA1, PLLA2, and PIS were $86 \%$, $64 \%$, and $61 \%$, respectively.

\section{Analysis}

Size exclusion chromatography (SEC) was carried out with a Shimadzu HPLC/SEC class-VP system equipped with a Shimadzu RID 10A differential refractive index detector and connected to four Styragel columns $\left(10^{2}, 10^{3}\right.$, $10^{4}$, and $10^{5} \AA$; Waters). Chloroform was used as mobile phase at a flow rate of $1 \mathrm{~mL} \mathrm{~min}^{-1}$ and low polydispersed polystyrene reference samples (Aldrich/Waters) were used for calibration.

${ }^{1} \mathrm{H}$ and ${ }^{13} \mathrm{C}$ nuclear magnetic resonance (NMR) spectra were obtained in a Bruker DRX $500(500$ and $125 \mathrm{MHz}$, respectively) or Bruker AC 200E (200 and $50 \mathrm{MHz}$, respectively). The samples $(20-100 \mathrm{mg}$ ) were dissolved in $\mathrm{CDCl}_{3}(0.5 \mathrm{~mL})$ using TMS as internal reference.

MALDI-TOFMS measurements were performed by using an Ettan MALDI-TOF mass spectrometer (Amersham Biosciences), equipped with a nitrogen laser emitting at $337 \mathrm{~nm}$ and operating at an acceleration voltage of $20 \mathrm{kV}$. The detection of positive ions was carried out in reflection mode and 200 laser shots were summed up per full spectrum. Angiotensin, adrenocorticotropic hormone (ACTH), and bovine cytochrome $\mathrm{C}$ were used for calibration. Stock solutions were prepared from the samples $\left(10 \mathrm{mg} \mathrm{mL}^{-1}\right)$, the matrix (1,8,9-trihydroxyanthracene; dithranol; $\left.10 \mathrm{mg} \mathrm{mL}^{-1}\right)$, and $\mathrm{NaI}\left(5 \mathrm{mg} \mathrm{mL}^{-1}\right)$ in chloroform/tetrahydrofuran (THF) $(1: 1, \mathrm{v} / \mathrm{v})$. Aliquots of $10 \mu \mathrm{L}$ of the sample, $25-80 \mu \mathrm{L}$ of the matrix, and 3-8 $\mu \mathrm{L}$ of $\mathrm{NaI}$ were mixed together. $0.5 \mu \mathrm{L}$ of this mixture was added onto the sample holders (stainless steel; $0.5 \mu \mathrm{L}$ ), and air-dried prior to analyses.

The addition of cationizing agent (e.g. NaI salt) in MALDI-TOFMS procedures presents at least one of the following outcomes: (i) the signal-to-noise ratio increases, (ii) the signals originated by other salts eventually present in the sample are suppressed, and (iii) the base-line is improved. ${ }^{11}$ The quality of the spectra obtained was significantly improved through the addition of $\mathrm{NaI}$ (the corresponding spectra without $\mathrm{NaI}$ salt addition are not shown), as well as the best sample-to-matrix-to-cationizing agent ratios.

The diffraction patterns of wide angle X-ray diffraction (WAXD) were recorded in a Rigaku Miniflex powder $\mathrm{X}$-ray diffractometer, using a monochromatic beam with wavelength $(\lambda)$ of $0.194 \mathrm{~nm}\left(\mathrm{FeK}_{\alpha}\right)$ or $0.154 \mathrm{~nm}\left(\mathrm{CuK}_{\alpha}\right)$, voltage of $30 \mathrm{kV}$, and electric current of $15 \mathrm{~mA}$. The intensities were collected from $2 \theta$ range of $3-60^{\circ}$ with step scanning mode of $0.02^{\circ}$. The powdered samples were annealed in a vacuum-oven at $90{ }^{\circ} \mathrm{C}$ for $48 \mathrm{~h}$ prior to the analyses.

The degrees of crystallinity $\left(\chi_{\mathrm{c}}\right)$ were obtained from WAXD profiles with curve decompositions following Gauss or Lorentz function fits as follows: the ratio of the area of crystalline peaks to the total area (crystalline peaks plus amorphous halo) was multiplied by 100 .

\section{Results and Discussion}

PLLA (1 and 2) and PIS were obtained, respectively, in bulk by ring-opening polymerization and by polycondensation via azeotropic distillation in order to be used as reagents in subsequent steps. Four products (I-IV) containing L-lactic acid, isosorbide, and succinate moieties were synthesized from different approaches by means of copolymerization techniques, i.e., using in all cases different feed reagents (see Scheme 1).

Table 2 presents the values of $\bar{M}_{n}$ and polydispersity index $\left(\overline{\mathrm{M}}_{\mathrm{w}} / \overline{\mathrm{M}}_{\mathrm{n}}\right)$ obtained for PLLA (1 and 2), PIS, and I-IV by SEC and MALDI-TOFMS, for comparison. The $\overline{\mathrm{M}}_{\mathrm{n}}$ values obtained by SEC for I-IV, as well as for PLLA (1 and 2) and PIS, were relatively low, ranging from 4.300 to $5.850 \mathrm{~g} \mathrm{~mol}^{-1}$ and from 2.300 to $9.100 \mathrm{~g} \mathrm{~mol}^{-1}$, respectively, showing that, in general, co-oligomers and oligomers were attained.

The low average molar mass obtained for PIS is related to the fact that $(i)$ isosorbide is a secondary diol and (ii) it presents two different hydroxyl groups, endo and exo, with different reactivities. ${ }^{4,22}$ The low average molar masses obtained for PLLA are associated with the relatively low purity of the monomer L-lactide used, which serves to the purpose of this study. Perego et al. ${ }^{21}$ also obtained PLLA with low average molar masses by using less pure L-lactide. In this work, when very pure L-lactide was used, PLLA with $\overline{\mathrm{M}}_{\mathrm{w}}$ up to $347.000 \mathrm{~g} \mathrm{~mol}^{-1}$ was obtained. The approach used for the synthesis of III revealed to be the most promising with respect to its average molar mass. Additional 


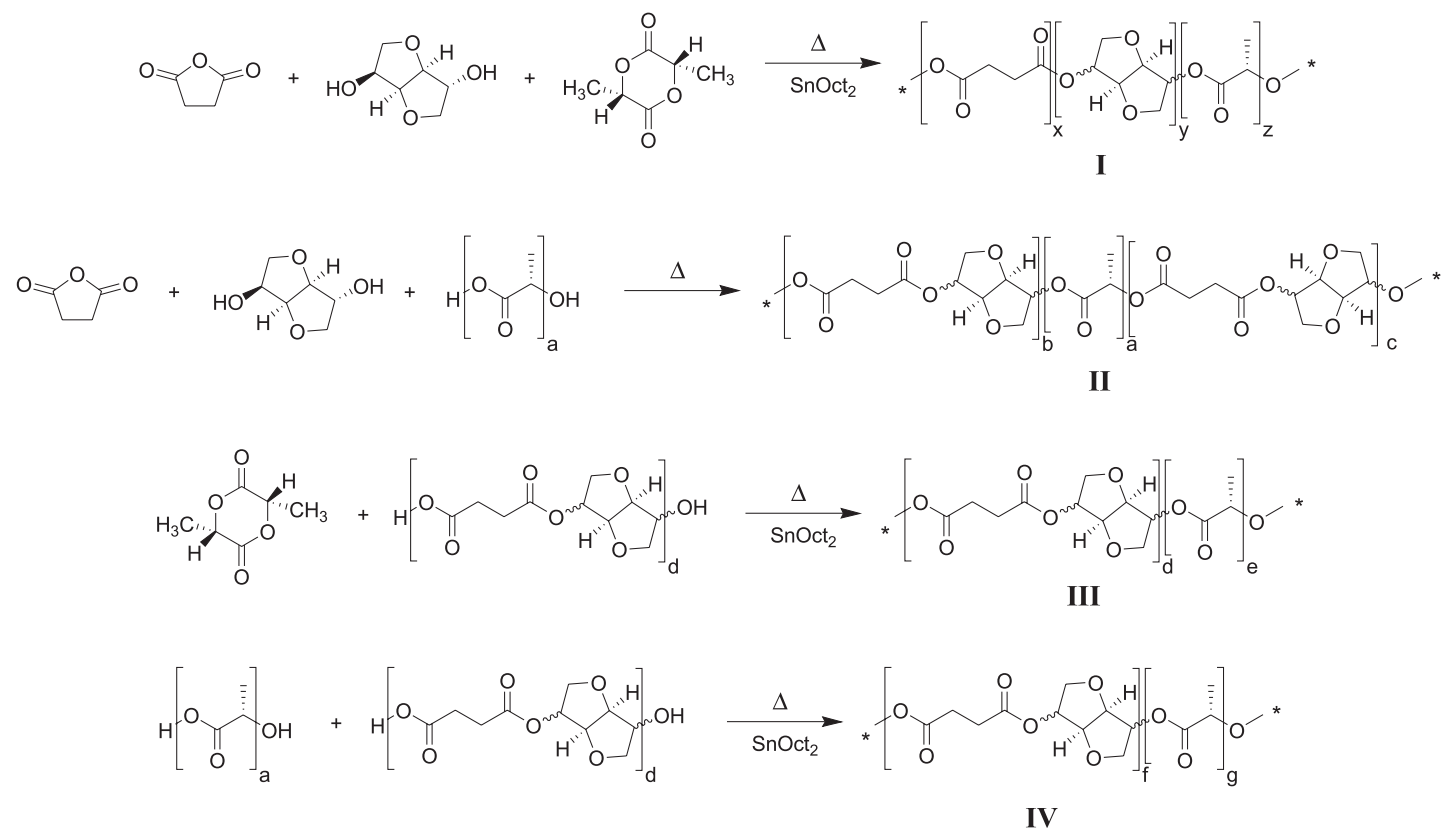

Scheme 1. Proposed chemical structures for the products I-IV. See experimental section, where $\mathrm{x}, \mathrm{y}$, and $\mathrm{z}$ denote the molar fraction of succinate, isosorbide, and L-lactic acid moieties randomly distributed along the co-oligomer chains, respectively. The indices a-g correspond to the number of the respective repeating units in each structure. The proposed structure for $\mathbf{I V}$ is representing only the overall acylic nucleophilic substitution stemmed from PIS hydroxyl end group attack.

Table 2. Mass compositions determined by ${ }^{1} \mathrm{H}$ NMR and values of $\bar{M}_{n}$ and polydispersity index $\left(\bar{M}_{w} / \bar{M}_{n}\right)$ obtained by SEC and MALDI-TOFMS, for the sake of comparison

\begin{tabular}{|c|c|c|c|c|c|c|}
\hline \multirow{2}{*}{ Run } & \multicolumn{2}{|c|}{ Composition measured / (wt.\%) } & \multicolumn{2}{|c|}{ MALDI-TOFMS } & \multicolumn{2}{|c|}{ SEC } \\
\hline & LLA $^{a}$ & $\mathrm{IS}^{\mathrm{b}}$ & $\overline{\mathrm{M}}_{\mathrm{n}} /\left(\mathrm{g} \mathrm{mol}^{-1}\right)$ & $\overline{\mathrm{M}}_{\mathrm{w}} / \overline{\mathrm{M}}_{\mathrm{n}}$ & $\overline{\mathrm{M}}_{\mathrm{n}} /\left(\mathrm{g} \mathrm{mol}^{-1}\right)$ & $\overline{\mathrm{M}}_{\mathrm{w}} / \overline{\mathrm{M}}_{\mathrm{u}}$ \\
\hline PLLA1 & - & - & - & - & 9.100 & 1.6 \\
\hline PLLA2 & - & - & 2.200 & 1.2 & 3.050 & 1.3 \\
\hline PIS & - & - & 1.750 & 1.2 & 2.300 & 1.4 \\
\hline $\mathbf{I}^{\mathrm{c}}$ & 62 & $38^{\mathrm{d}}$ & 1.800 & 1.2 & 4.300 & 1.6 \\
\hline $\mathbf{I I}^{\mathrm{c}}$ & 83 & 17 & 2.150 & 1.1 & 4.700 & 1.2 \\
\hline III $^{\mathrm{c}}$ & 61 & 39 & 1.900 & 1.1 & 4.550 & 1.4 \\
\hline $\mathbf{I V}^{\mathrm{c}}$ & 75 & 25 & 2.700 & 1.2 & 5.850 & 1.9 \\
\hline
\end{tabular}

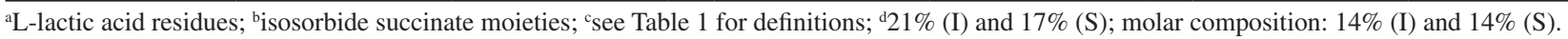

experiments starting from that approach produced materials with $\overline{\mathrm{M}}_{\mathrm{w}}$ ranged from 20.000 to $210.000 \mathrm{~g} \mathrm{~mol}^{-1}$.

The $\bar{M}_{n}$ values obtained by MALDI-TOFMS were $42-76 \%$ lower than those obtained by SEC. Two possible reasons can explain this difference: (i) SEC data calculations were based on polystyrene as reference, which may not reflect correctly the hydrodynamic volumes of the samples and (ii) lighter molecules can be preferentially desorbed and ionized, ${ }^{23}$ especially in the case of synthetic (co)polymers with polydispersity index higher than 1.2. ${ }^{23}$

Table 2 also presents the mass compositions of the products I-IV determined by ${ }^{1} \mathrm{H}$ NMR. The mass compositions ranged from $61-83 \%$ (LLA) to $39-17 \%$ (IS).

${ }^{13} \mathrm{C}$ NMR spectra (not shown) obtained for the homooligomers presented the following chemical shifts in the region of the carbonyl functional group: $169.6 \mathrm{ppm}$ (PLLA2) and 171.4 and $171.1 \mathrm{ppm}$ (PIS), in very good agreement with the data reported in literature. ${ }^{4,24}$

The ${ }^{13} \mathrm{C}$ NMR spectra obtained for I-IV in the expanded region of the carbonyl grouping (Figure 1) displayed either additional (I-III) or no additional (IV) peaks. A qualitative analysis revealed that product I exhibited ten additional peaks (171.4, 171.2, 171.1, 170.0, 169.8, 169.7, 169.5, 169.3, 169.2, and 169.0 ppm; Figure 1a), which could emerge from the interactions of the different moiety sequences randomly distributed along the co-oligomer chains, i.e., a random co-oligomer was attained. Similar results were observed by Abe et al..$^{25}$ when they reported the appearance of six additional peaks in the $\mathrm{C}=\mathrm{O}$ regions of ${ }^{13} \mathrm{C}$ NMR spectra obtained for random copolymers synthesized 

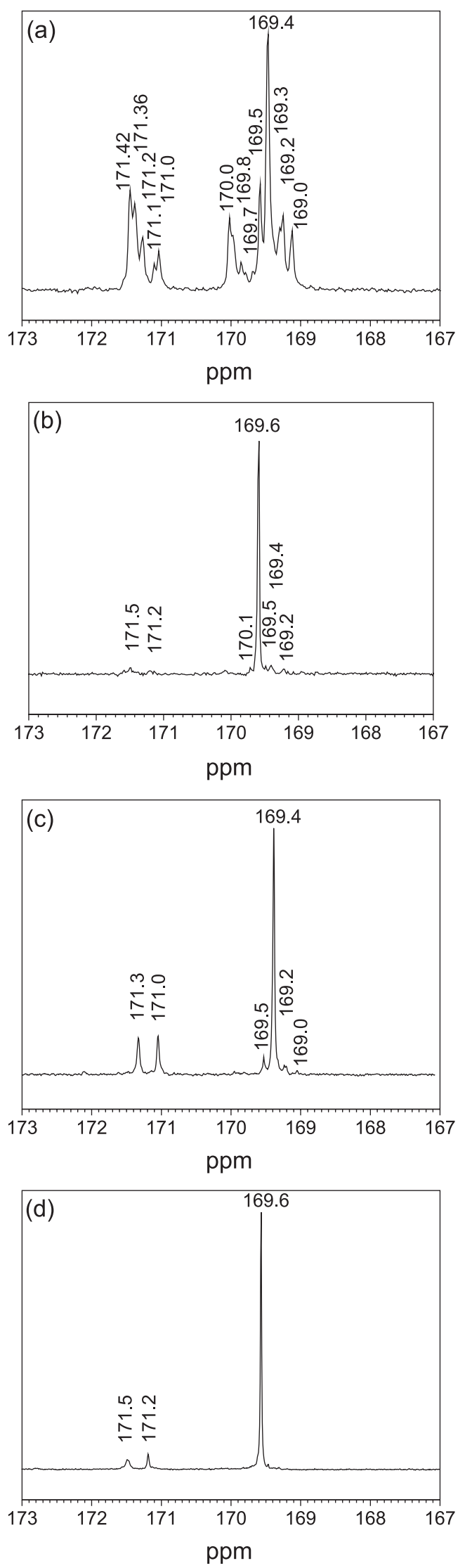

Figure 1. ${ }^{13} \mathrm{C}$ NMR spectra expanded in the carbonyl region obtained for the products (a) I, (b) II, (c) III, and (d) IV. through ring-opening copolymerization from monomer mixtures of (R)- $\beta$-butyrolactone and L-lactide.

Conversely, product IV displayed no extra peaks (Figure 1d), implying that this could be a block cooligomer showing lack of random sequences. ${ }^{8,26}$ Kricheldorf has obtained copolymers possessing almost block structures from transesterification reactions between two homopolymers. ${ }^{26}$

Although Hiki et al. ${ }^{27}$ have synthesized copolymers from ring-opening copolymerization of hydroxylterminated atactic PHB with L-lactide, the block nature of those products was stated based on the absence of signals due to the alternating HB-LA sequences in the $\mathrm{C}=\mathrm{O}$ regions of ${ }^{13} \mathrm{C}$ NMR spectra. They also claimed that the detrimental transesterification reactions have not happen during the block copolymerrizations. ${ }^{27}$

Products II and III showed four (170.1, 169.5, 169.4, $169.2 \mathrm{ppm}$; Figure 1b) and three $(169.5,169.2,169.0$ ppm; Figure 1c) extra peaks of very weak intensities, respectively. One possible interpretation of these results is that block co-oligomers were obtained, but mild secondary transesterification reactions occurred and shorter blocks (than those that would be formed if transesterification reactions would have not happened) are expected as a result.

In addition to ${ }^{13} \mathrm{C}$ NMR results, MALDI-TOFMS measurements were performed in order to give additional evidence on the co-oligomers formation, as well as on their structures. Figures 2a and b illustrate, respectively, both full and expanded region at mass-to-charge ratio $(\mathrm{m} / \mathrm{z}$ ) ranging from 1500 to 2000 of the MALDI-TOF mass spectra obtained for I using NaI salt.

Figure $2 b$ exhibits six series of peaks showing the variation of L-lactic acid residues along the series, plus four additional series of peaks exhibiting the variation of succinate and isosorbide moieties. The proposed adduct structures for the product $\mathbf{I}$ are depicted in Scheme 2.

The end groups shown in Schemes 2-4 are consistent with esterification and transesterification reactions involved in the formation of (co)polyesters, ${ }^{11,12,14}$ in addition to sodium-cationized (co)polyester chains terminated with hydroxyl (or carboxyl) and sodium carboxylate end groups formed during MALDI-TOFMS measurements. ${ }^{11,14}$

The calculated $\mathrm{m} / \mathrm{z}$ values for adducts $\left([\mathrm{M}+2 \mathrm{Na}-\mathrm{H}]^{+}\right.$, $[\mathrm{M}+\mathrm{Na}]^{+}$, or $[\mathrm{M}+\mathrm{H}]^{+}$) of the product $\mathbf{I}$ were obtained by applying equation 1 .

Adduct $m / z=100 \mathrm{x}+128 \mathrm{y}+72 \mathrm{z}+\mathrm{CE}+\mathrm{EG}$

where: $\mathrm{x}, \mathrm{y}$, and $\mathrm{z}$ correspond to the molar fraction of succinate, isosorbide, and L-lactic acid moieties randomly distributed along the co-oligomer chains, respectively; 100, 
128 , and 72 refer to the relative molar masses of succinate, isosorbide, and L-lactic acid residues, respectively; $\mathrm{CE}$ is the charged species and can assume values of 1,23 , and 46 referring to the relative atomic mass of a proton detached from the matrix, or one or two $\mathrm{Na}^{+}$stemmed from $\mathrm{NaI}$ salt, respectively; EG is the end group and can assume values
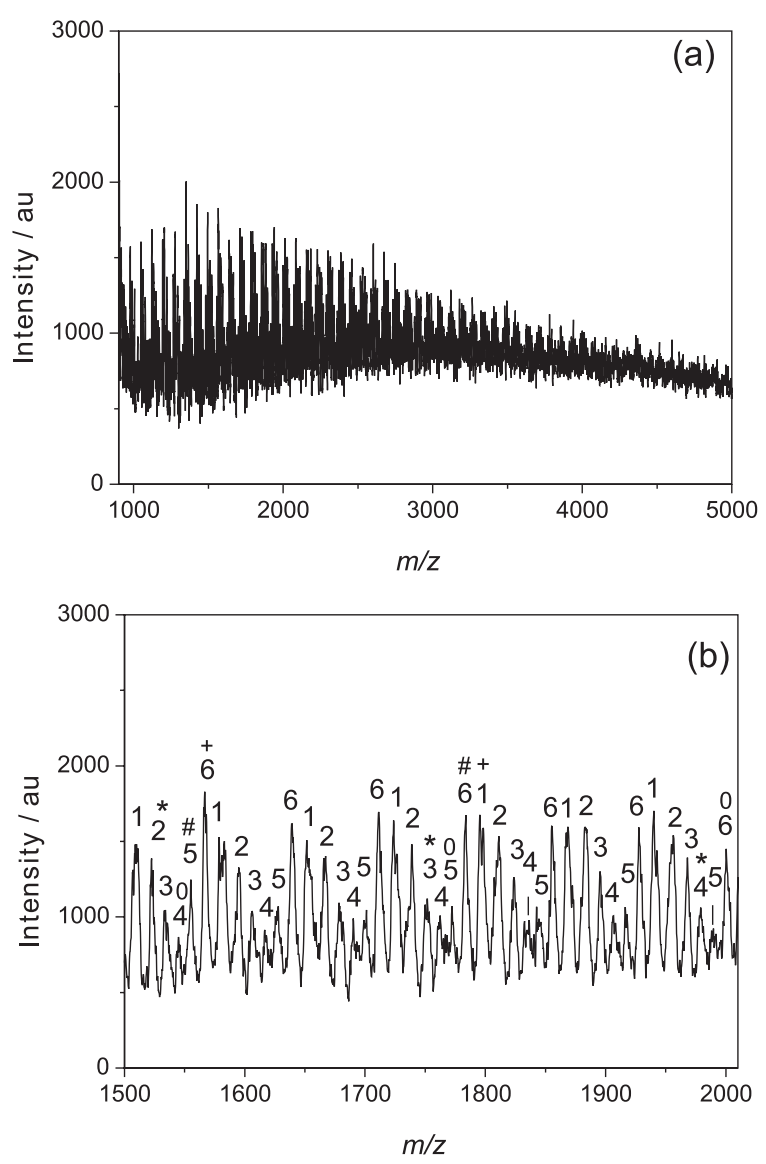

Figure 2. MALDI-TOF mass spectra of the product I acquired with $\mathrm{NaI}$ in (a) full region and (b) expanded region at $\mathrm{m} / \mathrm{z}$ ranging from 1500 to 2000.

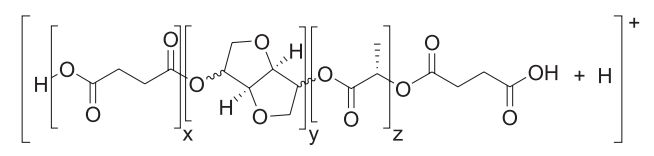

I-1

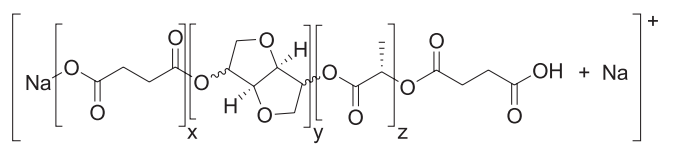

I-3 of 18,118 , and 146 corresponding to the relative molar masses of hydrogen atom and hydroxyl, hydrogen atom and succinyl residue, and isosorbide residue and hydroxyl, respectively.

It should be pointed out that artifacts due isobaric effects are ruled out since the relative molar masses of the monomer moieties involved (100 for succinate, 128 for isosorbide and 72 for L-lactic acid) have no multiplicity relationship, enabling sequence analysis from MALDITOFMS measurements.

The calculated and experimental $\mathrm{m} / \mathrm{z}$, values obtained for adducts of the product $\mathbf{I}$ appearing in Figure $2 \mathrm{~b}$ are presented in Table 3. The calculated and experimental $\mathrm{m} / \mathrm{z}$ values showed a good agreement (Table 3), suggesting that the product $\mathbf{I}$ is a co-oligomer. The presence of odd number of L-lactic acid moieties (Table 3) implies that intermolecular side transesterification reactions are involved.

Figures $3 \mathrm{a}$ and $\mathrm{b}$ show, respectively, both full and expanded region at $\mathrm{m} / \mathrm{z}$ ranging from 1500 to 2000 of the MALDI-TOF mass spectra obtained for II using NaI. Figure $3 \mathrm{~b}$ shows five series of peaks and exhibits several series of peaks in common with those shown in Figure 2b for the product $\mathbf{I}$. Again, the five series of peaks show the variation of L-lactic acid mers and three extra series of peaks exhibiting the variation of isosorbide succinate repeating units are also depicted.

Scheme 3 illustrates the proposed adduct structures for II and the calculated $\mathrm{m} / \mathrm{z}$ values for adducts $\left([\mathrm{M}+\mathrm{Na}]^{+}\right.$or $\left.[\mathrm{M}+\mathrm{H}]^{+}\right)$of the product $\mathbf{I I}$ was obtained from equation 2 shown below.

Adduct $m / z=228(\mathrm{~b}+\mathrm{c})+72 \mathrm{a}+\mathrm{CE}+\mathrm{EG}$

where: $\mathrm{b}$ plus $\mathrm{c}$ stand for the total number of isosorbide succinate repeating units in both side blocks, a refers to

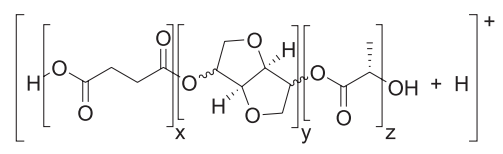

I-2

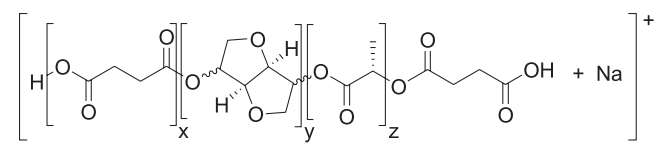

I-4

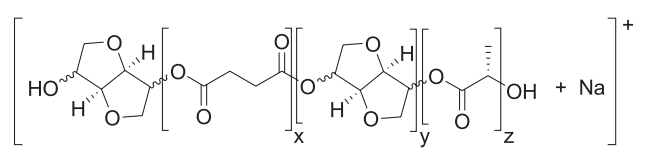


Table 3. Calculated and experimental $\mathrm{m} / \mathrm{z}$ values for adducts of the product $\mathbf{I}$

\begin{tabular}{|c|c|c|c|}
\hline Peak series $^{\mathrm{a}}$ & Adduct structures ${ }^{\mathrm{b}}$ & Calculated $m / z$ values ${ }^{\mathrm{c}}(\mathrm{x}, \mathrm{y}, \mathrm{z})^{\mathrm{d}}$ & Experimental $m / z$ values ${ }^{\mathrm{e}}$ \\
\hline 1 & I-2 & $\begin{array}{c}1507(4,4,8) ; 1579(4,4,9) ; 1651(4,4,10) ; 1723(4,4,11) ; \\
1795(4,4,12) ; 1867(4,4,13) ; 1939(4,4,14)\end{array}$ & $\begin{array}{c}1507.0 ; 1578.7 ; 1651.5 ; 1723.8 \\
\quad 1795.6 ; 1867.3 ; 1940.2\end{array}$ \\
\hline 2 & I-5 & $\begin{array}{c}1525(5,5,3) ; 1597(5,5,4) ; 1669(5,5,5) ; 1741(5,5,6) \\
1813(5,5,7) ; 1885(5,5,8) ; 1957(5,5,9)\end{array}$ & $\begin{array}{c}1523.7 ; 1595.0 ; 1667.3 ; 1738.9 \\
1811.2 ; 1883.0 ; 1954.8\end{array}$ \\
\hline 3 & I-1 & $\begin{array}{c}1535(4,4,7) ; 1607(4,4,8) ; 1679(4,4,9) ; 1751(4,4,10) ; \\
1823(4,4,11) ; 1895(4,4,12) ; 1967(4,4,13)\end{array}$ & $\begin{array}{l}1535.3 ; 1606.0 ; 1678.2 ; 1750.0 \\
\quad 1823.9 ; 1895.4 ; 1968.0\end{array}$ \\
\hline 4 & I-1 & $\begin{array}{c}1547(5,5,4) ; 1619(5,5,5) ; 1691(5,5,6) ; 1763(5,5,7) ; \\
1835(5,5,8) ; 1907(5,5,9) ; 1979(5,5,10)\end{array}$ & $\begin{array}{c}1545.1 ; 1617.9 ; 1690.1 ; 1762.5 \\
1836.4 ; 1906.5 ; 1979.1\end{array}$ \\
\hline 5 & I-2 & $\begin{array}{c}1555(2,2,15) ; 1627(2,2,16) ; 1699(2,2,17) ; 1771(2,2,18) \\
1843(2,2,19) ; 1915(2,2,20) ; 1987(2,2,21)\end{array}$ & $\begin{array}{l}1555.2 ; 1627.9 ; 1699.0 ; 1772.2 \\
1842.5 ; 1916.4 ; 1988.1\end{array}$ \\
\hline 6 & $\mathrm{I}-2$ & $\begin{array}{c}1567(3,3,12) ; 1639(3,3,13) ; 1711(3,3,14) ; 1783(3,3,15) \\
1855(3,3,16) ; 1927(3,3,17) ; 1999(3,3,18)\end{array}$ & $\begin{array}{l}1567.0 ; 1639.0 ; 1711.5 ; 1783.8 \\
\quad 1855.2 ; 1927.6 ; 2000.3\end{array}$ \\
\hline *f & I-1 & $1523(3,3,10) ; 1751(4,4,10) ; 1979(5,5,10)$ & $1523.7 ; 1750.0 ; 1979.1$ \\
\hline $0^{\mathrm{f}}$ & I-4 & $1545(3,3,10) ; 1773(4,4,10) ; 2001(5,5,10)$ & $1545.1 ; 1772.2 ; 2000.3$ \\
\hline$t^{\mathrm{f}}$ & $\mathbf{I}-2$ & $1567(3,3,12) ; 1795(4,4,12) ; 2023(5,5,12)$ & $1566.7 ; 1795.6 ; 2023.8^{\mathrm{g}}$ \\
\hline$\#^{\mathrm{f}}$ & $\mathbf{I}-3$ & $1555(2,2,13) ; 1783(3,3,13) ; 2011(4,4,13)$ & $1555.2 ; 1783.8 ; 2011.5^{\mathrm{g}}$ \\
\hline
\end{tabular}

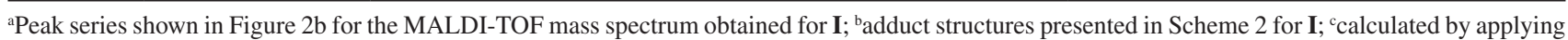
equation $1 ;{ }^{\mathrm{d}} \mathrm{x}, \mathrm{y}$, and $\mathrm{z}$ correspond to, respectively, the molar fraction of succinate, isosorbide and L-lactic acid residues randomly distributed over the co-oligomer chains; ${ }^{e}$ experimental data; ${ }^{\mathrm{f}}$ new peak series showing the variation of succinate and isosorbide moieties along those series; ${ }^{\mathrm{g}} \mathrm{values}$ out of the previously established range.
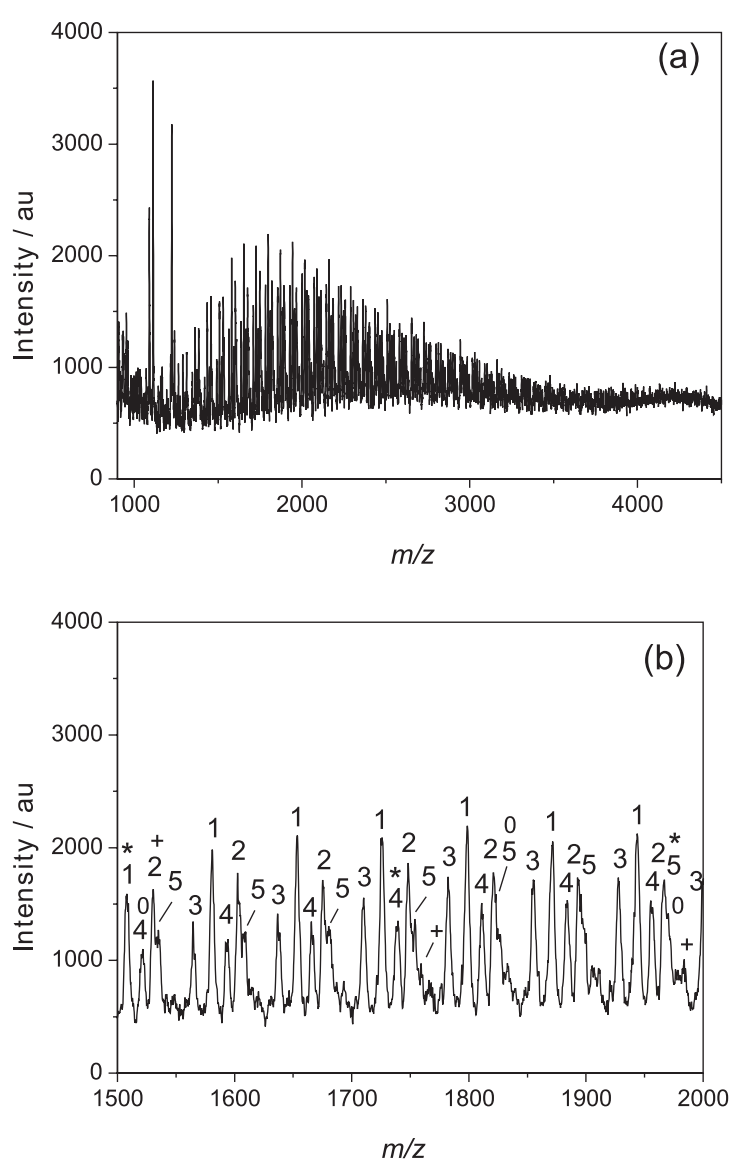

Figure 3. MALDI-TOF mass spectra of the product II acquired with $\mathrm{NaI}$ in (a) full region and (b) expanded region at $\mathrm{m} / \mathrm{z}$ ranging from 1500 to 2000 .
L-lactic acid repeating unit, and 228 correspond to the relative molar mass of isosorbide succinate repeating unit (for the definition of other terms, see equation 1).

As already mentioned, MALDI-TOFMS can be used to obtain sequence information since 228 is neither equal to nor multiple of 72 . The calculated and experimental $\mathrm{m} / \mathrm{z}$ values for adducts of the product II shown in Figure $3 \mathrm{~b}$ are summarized in Table 4. The theoretical and experimental $\mathrm{m} / \mathrm{z}$ values are in good agreement (Table 4), implying that II is a co-oligomer.

Both full and expanded region at $\mathrm{m} / \mathrm{z}$, ranging from 1500 to 2000 MALDI-TOF mass spectra obtained for IV using $\mathrm{NaI}$ are shown in Figure $4 \mathrm{a}$ and b, respectively. Figure $4 \mathrm{~b}$ shows three series of peaks exhibiting the variation of L-lactic acid repeating units. In general, these three series of peaks are quite close to the first three displayed in the spectrum obtained for II (Figures $4 \mathrm{~b}$ and $3 \mathrm{~b}$ ), indicating structural similarities.

The MALDI-TOF mass spectra of III acquired with $\mathrm{NaI}$ for both full and expanded region at $\mathrm{m} / \mathrm{z}$ ranging from 1500 to 2000 are illustrated in Figure 5a and b, respectively. Three series of peaks showing the variation of L-lactic acid mers and four series of peaks exhibiting the variation of isosorbide succinate repeating units along each series are displayed in Figure 5b. Scheme 4 shows the suggested adduct structures for III. The calculated $\mathrm{m} / \mathrm{z}$ values for adducts $\left([\mathrm{M}+\mathrm{Na}]^{+}\right.$or $\left.[\mathrm{M}+\mathrm{H}]^{+}\right)$of the product III were obtained based on equation 2. Table 5 contains 
$\left[{ }_{0}^{[O} \prod_{0}\right.$

II-1

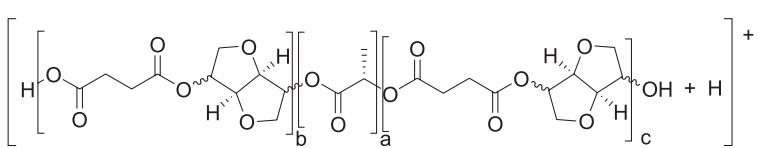

II-2

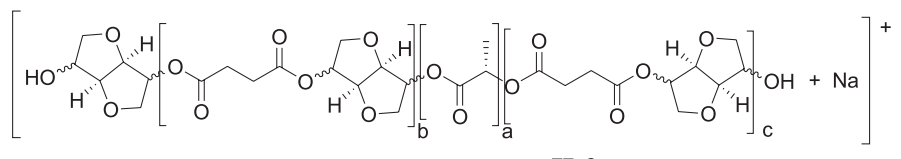

II-3

Scheme 3. Proposed adduct structures for the product II.

Table 4. Calculated and experimental $\mathrm{m} / \mathrm{z}$ values for adducts of the product II

\begin{tabular}{|c|c|c|c|}
\hline Peak series $^{\mathrm{a}}$ & Adduct structures ${ }^{\mathrm{b}}$ & Calculated $m / z$ values ${ }^{\mathrm{c}}(\mathrm{b}+\mathrm{c}, \mathrm{a})^{\mathrm{d}}$ & Experimental $m / z$ values ${ }^{\mathrm{e}}$ \\
\hline $1^{\mathrm{f}}$ & II-1 & $\begin{array}{c}1511 \text { (2,13); } 1583(2,14) ; 1655(2,15) ; 1727(2,16) ; \\
1799(2,17) ; 1871(2,18) ; 1943(2,19)\end{array}$ & $\begin{array}{l}1509.3 ; 1580.8 ; 1653.6 ; 1725.0 ; \\
\quad 1798.8 ; 1871.6 ; 1943.8\end{array}$ \\
\hline $2^{\mathrm{f}}$ & II-2 & $\begin{array}{c}1531(6,2) ; 1603(6,3) ; 1675(6,4) ; 1747(6,5) ; \\
1819(6,6) ; 1891(6,7) ; 1963(6,8)\end{array}$ & $\begin{array}{c}1530.4 ; 1602.6 ; 1675.2 ; 1748.2 \\
1820.8 ; 1892.7 ; 1961.9\end{array}$ \\
\hline $3^{\mathrm{f}}$ & II-2 & $\begin{array}{c}1567(3,12) ; 1639(3,13) ; 1711(3,14) ; 1783(3,15) ; \\
1855(3,16) ; 1927(3,17) ; 1999(3,18)\end{array}$ & $\begin{array}{c}1564,5 ; 1636,8 ; 1710,2 ; 1782,2 ; \\
1854,9 ; 1927,6 ; 1999,2\end{array}$ \\
\hline 4 & II-3 & $\begin{array}{c}1525(5,3) ; 1597(5,4) ; 1669(5,5) ; 1741(5,6) ; \\
1813(5,7) ; 1885(5,8) ; 1957(5,9)\end{array}$ & $\begin{array}{c}1522.9 ; 1594.3 ; 1667.2 ; 1739.6 ; \\
1810.9 ; 1884.0 ; 1955.3\end{array}$ \\
\hline 5 & II-1 & $\begin{array}{c}1535 \text { (4,7); } 1607(4,8) ; 1679(4,9) ; 1751(4,10) ; \\
1823(4,11) ; 1895(4,12) ; 1967(4,13)\end{array}$ & $\begin{array}{c}1534.8 ; 1609.0 ; 1680.3 ; 1753.0 \\
1823.1 ; 1894.0 ; 1966.9\end{array}$ \\
\hline$* \mathrm{~g}$ & II-1 & $1511(2,13) ; 1739(3,13) ; 1967(4,13)$ & $1509.3 ; 1739.6 ; 1966.9$ \\
\hline $0^{\mathrm{g}}$ & II-1 & $1523(3,10) ; 1751(4,10) ; 1979(5,10)$ & $1522.9 ; 1753.0 ; 1978.2$ \\
\hline$+^{g}$ & II-2 & $1531(6,2) ; 1759(7,2) ; 1987(8,2)$ & $1530.4 ; 1759.2 ; 1985.1$ \\
\hline
\end{tabular}

aPeak series depicted in Figure $3 \mathrm{~b}$ for the MALDI-TOF mass spectrum obtained for II; badduct structures presented in Scheme 3 for II; ${ }^{\mathrm{c}} \mathrm{calculated}$ by applying equation 2; ${ }^{\mathrm{d}}$ both $\mathrm{b}$ and $\mathrm{c}$ (which were added up) and a refer to the number of isosorbide succinate and L-lactic acid repeating units, respectively; experimental data; ${ }^{\mathrm{f}}$ those peaks were also observed in the MALDI-TOF mass spectrum obtained for the product IV (Figures $3 \mathrm{~b}$ and $4 \mathrm{~b}$ ); ${ }^{\mathrm{g}}$ new peak series showing the variation of isosorbide succinate repeating units along those series.

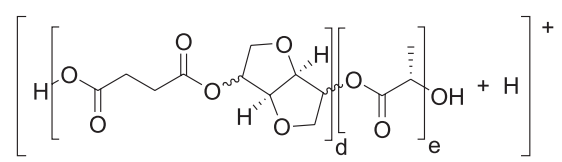

III-1

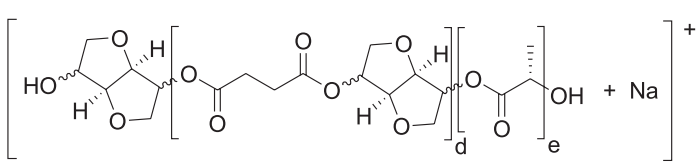

III-2

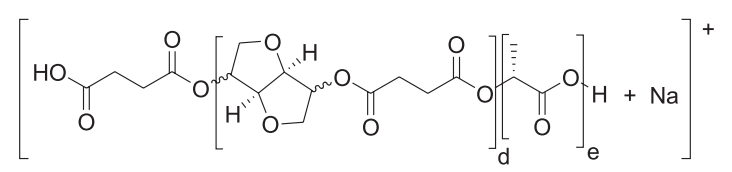

III-3

Scheme 4. Proposed adduct structures for the product III.

both the calculated and the experimental $\mathrm{m} / \mathrm{z}$ values for adducts of III. The co-oligomer nature of the product III is evidenced by the good agreement between the calculated and experimental $\mathrm{m} / \mathrm{z}$ values (Table 5).

The presence of odd and even numbers of L-lactic acid repeating units are expected for adducts of $\mathbf{I V}$, owing to transesterification reactions involving both PIS and PLLA hydroxyl end groups as nucleophilic agents. On the other hand, odd numbers of L-lactic acid repeating units given in Table 5 for adducts of III and shown in Table 4 for adducts of II suggest that undesirable side intermolecular transesterification reactions took place. As mentioned, mild secondary transesterification reactions were indicated (by additional peaks of very weak intensities) by ${ }^{13} \mathrm{C} \mathrm{NMR}$ qualitative analysis for the products II and III.

Literature data show the presence of odd and even 

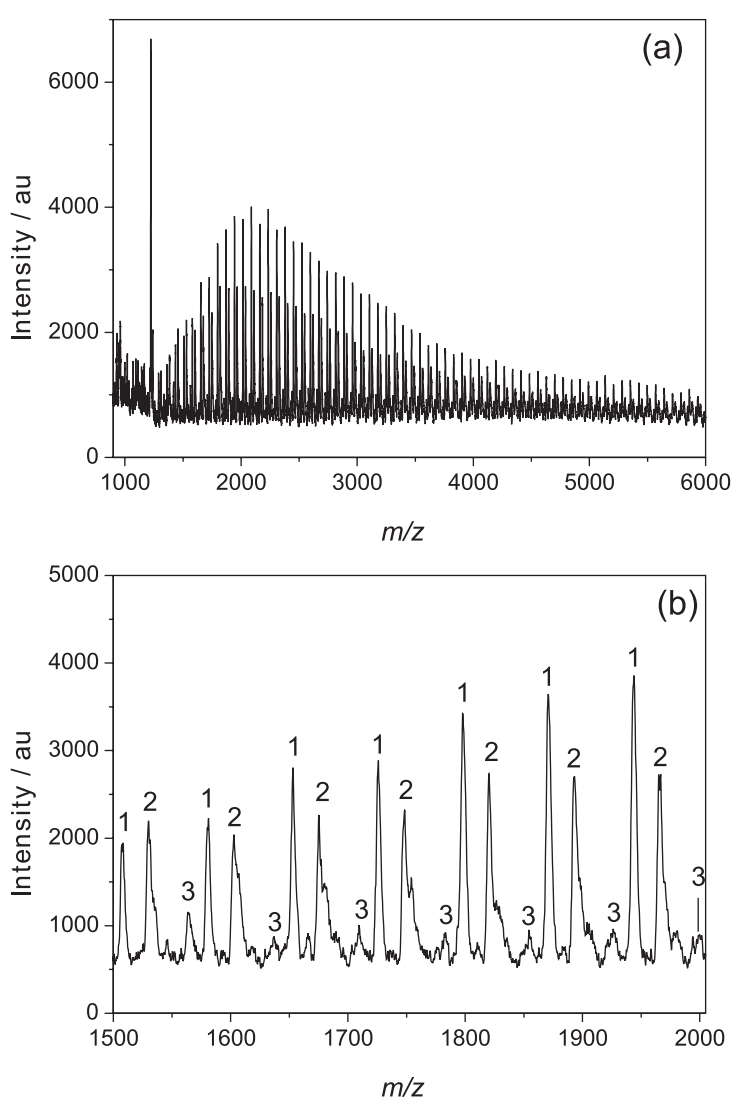

Figure 4. MALDI-TOF mass spectra of the product IV acquired with $\mathrm{NaI}$ in (a) full region and (b) expanded region at $\mathrm{m} / \mathrm{z}$ ranging from 1500 to 2000 .
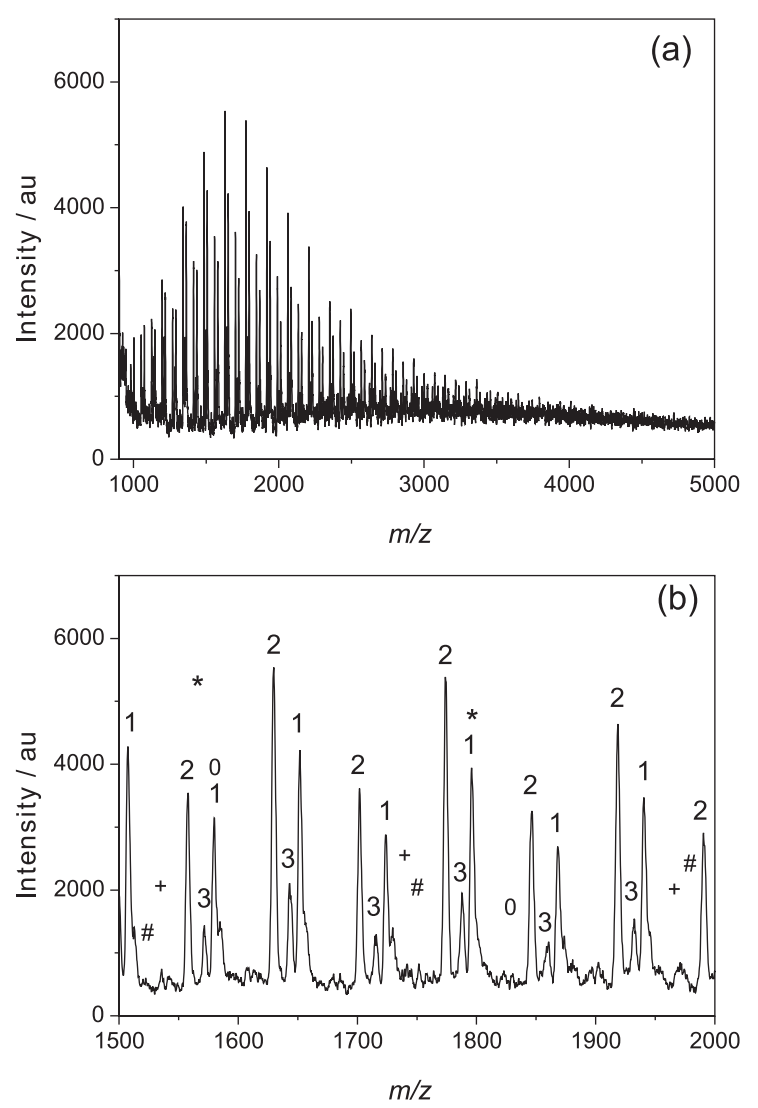

Figure 5. MALDI-TOF mass spectra of the product III acquired with $\mathrm{NaI}$ in (a) full region and (b) expanded region at $\mathrm{m} / \mathrm{z}$ ranging from 1500 to 2000 .

Table 5. Calculated and experimental $\mathrm{m} / \mathrm{z}$ values for adducts of the product III

\begin{tabular}{|c|c|c|c|}
\hline Peak series ${ }^{\mathrm{a}}$ & Adduct structures ${ }^{\mathrm{b}}$ & Calculated $m / z$ values ${ }^{\mathrm{c}}(\mathrm{d}, \mathrm{e})^{\mathrm{d}}$ & Experimental $m / z$ values ${ }^{\mathrm{e}}$ \\
\hline 1 & III-1 & $\begin{array}{c}1507(4,8) ; 1579(4,9) ; 1651(4,10) ; 1723(4,11) ; \\
1795(4,12) ; 1867(4,13) ; 1939(4,14)\end{array}$ & $\begin{array}{c}1507.5 ; 1580.1 ; 1651.8 ; 1723.8 \\
1795.8 ; 1868.1 ; 1940.4\end{array}$ \\
\hline 2 & III-3 & $\begin{array}{c}1557(4,7) ; 1629(4,8) ; 1701(4,9) ; 1773(4,10) ; \\
1845(4,11) ; 1917(4,12) ; 1989(4,13)\end{array}$ & $\begin{array}{c}1558.0 ; 1629.9 ; 1701.9 ; 1774.0 \\
1846.6 ; 1918.5 ; 1990.5\end{array}$ \\
\hline 3 & III-2 & $\begin{array}{l}1573(3,10) ; 1645(3,11) ; 1717(3,12) ; \\
1789(3,13) ; 1861(3,14) ; 1933(3,15)\end{array}$ & $\begin{array}{l}1571.6 ; 1643.1 ; 1715.9 \\
1787.8 ; 1860.6 ; 1932.3\end{array}$ \\
\hline$* \mathrm{f}$ & III-1 & $1567(3,12) ; 1795(4,12) ; 2023(5,12)$ & $1567.1 ; 1795.8 ; 2024.0^{\mathrm{g}}$ \\
\hline $0^{\mathrm{f}}$ & III-1 & $1579(4,9) ; 1807(5,9) ; 2035(6,9)$ & $1580.1 ; 1808.7 ; 2033.4^{g}$ \\
\hline$t^{\mathrm{f}}$ & III-2 & $1513(4,6) ; 1741(5,6) ; 1969(6,6)$ & $1512.8 ; 1741.6 ; 1968.8$ \\
\hline$\#^{\mathrm{f}}$ & III-2 & $1525(5,3) ; 1753(6,3) ; 1981(7,3)$ & $1524.6 ; 1751.5 ; 1980.1$ \\
\hline
\end{tabular}

aPeak series shown in Figure $5 \mathrm{~b}$ for the MALDI-TOF mass spectrum obtained for III; badduct structures presented in Scheme 4 for III; ${ }^{\mathrm{c}}$ calculated based on equation $2 ;{ }^{\mathrm{d}} \mathrm{d}$ and e refer to the number of isosorbide succinate and L-lactic acid repeating units, respectively; ${ }^{\mathrm{e}}$ experimental data; ${ }^{\mathrm{f}} \mathrm{new}$ peak series showing the variation of isosorbide succinate repeating units along those series; ${ }^{\mathrm{g}}$ values out of the previously established range.

numbers of L-lactic acid repeating units obtained by MALDI-TOFMS for poly(L-lactide), even when synthesized at mild conditions. ${ }^{28-30}$ Moreover, the obtained products were almost $100 \%$ isotactic, i.e., racemization did not take place. ${ }^{29,30}$ Lee et al. ${ }^{31}$ also observed by MALDITOFMS odd and even numbers of L-lactic acid mers in their block copolymers synthesized via ring-opening copolymerization of L-lactide with poly(ethylene oxide) or poly(ethylene glycol).

MALDI-TOFMS has been used to obtain sequence information on synthetic copolymer structures..$^{11,14,15,31,32}$ For example, a good agreement between experimental and calculated $\mathrm{m} / \mathrm{z}$ data has been used as evidence that copolymer structures were attained..$^{11,14,15,31,32}$ In a similar 
manner, our work was also based on that assumption, in addition to using supporting techniques.

WAXD was used as supporting technique to determine the degrees of crystallinity of the powdered samples previously annealed. The samples of PIS and I were not annealed. The diffraction pattern obtained for PLLA2 is similar to that reported in literature, ${ }^{33,34}$ while the diffraction pattern obtained for PIS showed, as expected, ${ }^{4}$ only an amorphous halo, characteristic of non-crystalline samples. The diffraction patterns obtained for II-IV are comparable with that obtained for PLLA2, whilst that obtained for I is comparable with that of PIS (see Supplementary Information). This is strong evidence that while $\mathbf{I}$ is a fully random copolymer, II-IV preserves blocks of L-lactic acid in its structure.

The degrees of crystallinity (Table 6) were obtained from WAXD profiles with curve decompositions following Gauss or Lorentz function fits (Supplementary Information). They amount to $71 \%$ (PLLA2), 0\% (PIS), 0\% (I), 41\% (II), $40 \%$ (III), and $52 \%$ (IV). Shorter blocks and loss in crystallinity are expected as the consequence of undesirable side transesterification reactions. Therefore, the data presented in Table 6 confirms the occurrence of mild secondary transesterification reactions involved during the syntheses of II and III.

Table 6. Degrees of crystallinity obtained by WAXD for the powdered samples previously annealed $\left(48 \mathrm{~h}\right.$ at $\left.90{ }^{\circ} \mathrm{C}\right)$

\begin{tabular}{cc}
\hline Run & $\chi_{\mathrm{c}} /(\%)^{\mathrm{a}}$ \\
\hline PLLA2 & 71 \\
PIS & $-^{\mathrm{b}}$ \\
I & $-{ }^{\mathrm{b}}$ \\
II & 41 \\
III & 40 \\
IV & 52 \\
\hline
\end{tabular}

a Degree of crystallinity; bobserved only an amorphous halo for each sample, which is expected for the scattering patterns produced by noncrystalline samples.

\section{Conclusions}

Four types of products (I-IV) with low average molar masses were synthesized from different approaches via copolymerization techniques. The calculated $\mathrm{m} / \mathrm{z}$ values for adducts of I-IV were in good agreement with the experimental values observed by MALDI-TOFMS, indicating that co-oligomers were obtained.

Although the analysis of ${ }^{13} \mathrm{C}$ NMR data was done in qualitative terms, the findings were consistent with those attained by MALDI-TOFMS. ${ }^{13} \mathrm{C}$ NMR data indicated that mild secondary transesterification reactions took place during the syntheses of II and III and blocks of shorter size (than those that would be formed if transesterification reactions would have not happened) are expected as a result. MALDI-TOFMS data also suggested that undesirable side intermolecular transesterification reactions were involved during the production of I-III. The WAXD profiles showed that $\mathbf{I}$ is completely amorphous and II-IV are semicrystalline. The degrees of crystallinity obtained by WAXD showed that a mild loss in crystallinity occurred for II and III, suggesting a shortening of the blocks due to side transesterification reactions, in agreement with ${ }^{13} \mathrm{C} N M R$ data. The data obtained by MALDI-TOFMS together with those by ${ }^{13} \mathrm{C}$ NMR and WAXD gave evidence that random (I) and block (II-IV) co-oligomers were attained. The most promising approach to obtain products with higher average molar masses towards biomaterial application was that used to synthesize the product III.

\section{Acknowledgments}

The authors thank CNPq, CAPES and FAPESP for financial support and Dr. Isaura N. Toma (Department of Biochemistry, Institute of Chemistry, USP) for MALDITOF mass spectra acquisitions.

\section{Supplementary Information}

Supplementary data are available free of charge at http:jbcs.sbq.org.br, as PDF file.

\section{References}

1. Huang, S. J. In Comprehensive Polymer Science: The Synthesis, Characterization, Reactions and Applications of Polymers; Eastmond, G. C.; Ledwith, A.; Russo, S.; Sigwalt, P., eds.; Pergamon Press: New York, 1989, vol. 8, pp. 598, 599.

2. Middleton, J. C.; Tipton, A. J.; Biomaterials 2000, 21, 2335.

3. Albertsson, A. C.; Karlsson, S. In Comprehensive Polymer Science, First Supplement; Aggarwal, S. L.; Russo, S., eds.; Pergamon Press: New York, 1992, pp. 285-297.

4. Okada, M.; Okada, Y.; Aoi, K.; J. Polym. Sci., Part A: Polym. Chem. 1995, 33, 2813.

5. Thiem, J.; Lüders, H.; Polym. Bull. 1984, 11, 365.

6. Stoss, P.; Hemmer, R.; Adv. Carbohydr. Chem. Biochem. 1991, 49, 93.

7. Schilling, L. B.; FEMS Microbiol. Rev. 1995, 16, 101.

8. Kricheldorf, H. R.; J. Macromol. Sci., Rev. Macromol. Chem. Phys. 1997, C37, 599.

9. Kricheldorf, H. R.; Behnken, G.; Sell, M.; J. Macromol. Sci., Part A: Pure Appl. Chem. 2007, 44, 679. 
10. Odian, G.; Principles of Polymerization, Willey: New York, 2004.

11. Pasch, H.; Schrepp, W.; MALDI-TOF Mass Spectometry of Synthetic Polymers, Springer: New York, 2003.

12. Shyamroy, S.; Garnaik, B.; Sivaram, S.; J. Polym. Sci., Part A: Polym. Chem. 2005, 43, 2164.

13. Saeed, K. A.; Ayorinde, F. O.; Eribo, B. E.; Gordon, M.; Collier, L.; Rapid Commun. Mass Spectrom. 1999, 13, 1951.

14. Adamus, G.; Rizzarelli, P.; Montaudo, M. S.; Kowalczuk, M.; Montaudo, G.; Rapid Commun. Mass Spectrom. 2006, 20, 804.

15. Alicata, R.; Barbuzzi, T.; Giuffrida, M.; Ballistreri, A.; Rapid Commun. Mass Spectrom. 2006, 20, 568.

16. Borda, J.; Kéki, S.; Bodnár, I.; Németh, N.; Zsuga, M.; Polym. Adv. Technol. 2006, 17, 945.

17. Libiszowski, J.; Kowalski, A.; Duda, A.; Penczek, S.; Macromol. Chem. Phys. 2002, 203, 1694.

18. Shringer, R. L.; Struck, H. C.; Org. Synth. 1932, 12, 66.

19. Joziasse, C. A. P.; Grijpma, D. W.; Bergsma, J. E.; Cordewener, F. W.; Bos, R. R. M.; Pennings, A. J.; Colloid Polym. Sci. 1998, $276,968$.

20. Garlotta, D.; J. Polym. Environ. 2001, 9, 63.

21. Perego, G.; Cella, G. D.; Bastioli, C.; J. Appl. Polym. Sci. 1996, $59,37$.

22. Hopton, F. J.; Thomas, H. S.; Can. J. Chem. 1969, 47, 2395.

23. Montaudo, G.; Garozzo, D.; Montaudo, M. S.; Puglisi, C.; Samperi, F.; Macromolecules 1995, 28, 7983.
24. Ajioka, M.; Enomoto, K.; Suzuki, K.; Yamaguchi, A.; Bull. Chem. Soc. Jpn. 1995, 68, 2125.

25. Abe, H.; Doi, Y.; Hori, Y.; Haghwara, T.; Polymer 1997, 39, 59.

26. Kricheldorf, H. R.; Makromol. Chem. 1978, 179, 2133.

27. Hiki, S.; Miyamoto, M.; Kimura, Y.; Polymer 2000, 41, 7369.

28. Montaudo, G.; Montaudo, M. S.; Puglisi, C.; Samperi, F.; Spassky, N.; Leborgne, A.; Wisniewski, M.; Macromolecules 1996, 29, 6461.

29. Kowalski, A.; Libiszowski, J.; Duda, A.; Penczek, S.; Macromolecules 2000, 33, 1964.

30. Jalabert, M.; Fraschini, C.; Prud'Homme, R. E.; J. Polym. Sci., Part A: Polym. Chem. 2007, 45, 1944.

31. Lee, H.; Chang, T.; Lee, D.; Shin, M. S.; Ji, H.; Nonidez, W. K.; Mays, J. W.; Anal. Chem. 2001, 73, 1726.

32. Carroccio, S.; Rizzarelli, P.; Puglisi, C.; Rapid Commun. Mass Spectrom. 2000, 14, 1513.

33. Cho, J.; Baratian, S.; Kim, J.; Yeh, F.; Hsiano, B. S.; Runt, J.; Polymer 2003, 44, 711.

34. Mano, J. F.; Wang, Y.; Viana, J. C.; Denchev, Z.; Oliveira, M. J.; Macromol. Mater. Eng. 2004, 289, 910.

Received: October 24, 2008

Web Release Date: August 7, 2009

FAPESP helped in meeting the publication costs of this article. 


\section{Synthesis and Structural Characterization of Block and Random Low Molecular Weight Copolymers Composed of L-lactic Acid and Isosorbide Succinate Moieties}

\section{Romeu Casarano, ${ }^{a}$ Denise F. S. Petri, ${ }^{a}$ Michael Jaffe ${ }^{b}$ and Luiz H. Catalani ${ }^{*, a}$}

${ }^{a}$ Instituto de Química, Universidade de São Paulo, 05513-970 São Paulo-SP, Brazil

${ }^{b}$ Medical Device Concept Laboratory, New Jersey Institute of Technology, Newark, USA

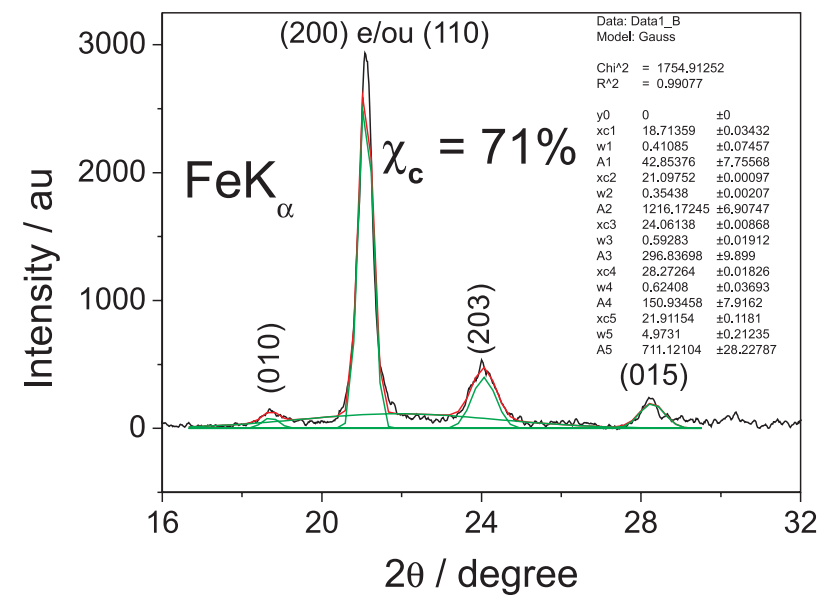

Figure S1. WAXD patterns obtained for powdered samples previously annealed ( $48 \mathrm{~h}$ at $90^{\circ} \mathrm{C}$ ) of PLLA2 with curve decompositions following Gauss function fit $\left(\mathrm{R}^{2}=0.99\right)$. "A5" corresponds to the amorphous halo areas.

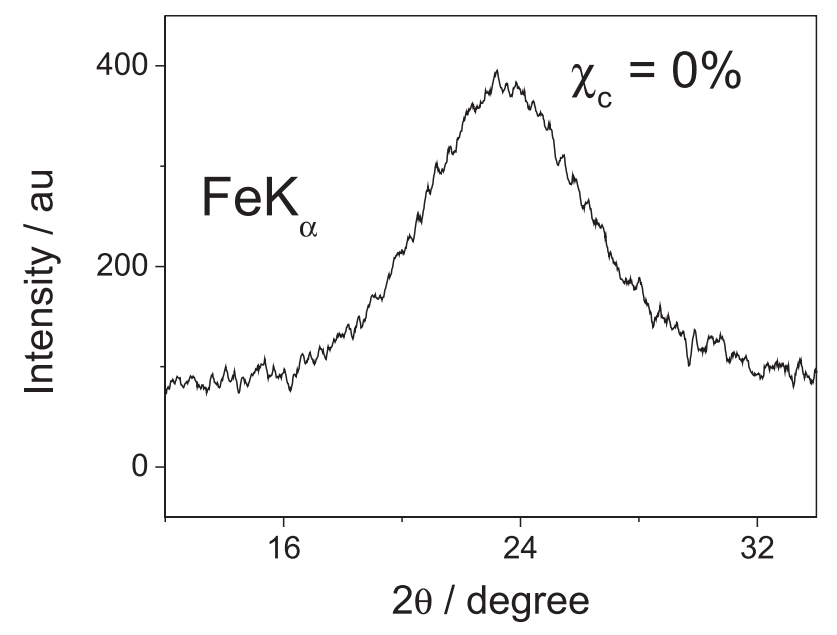

Figure S2. WAXD patterns obtained for powdered samples of PIS.

*e-mail: catalani@usp.br

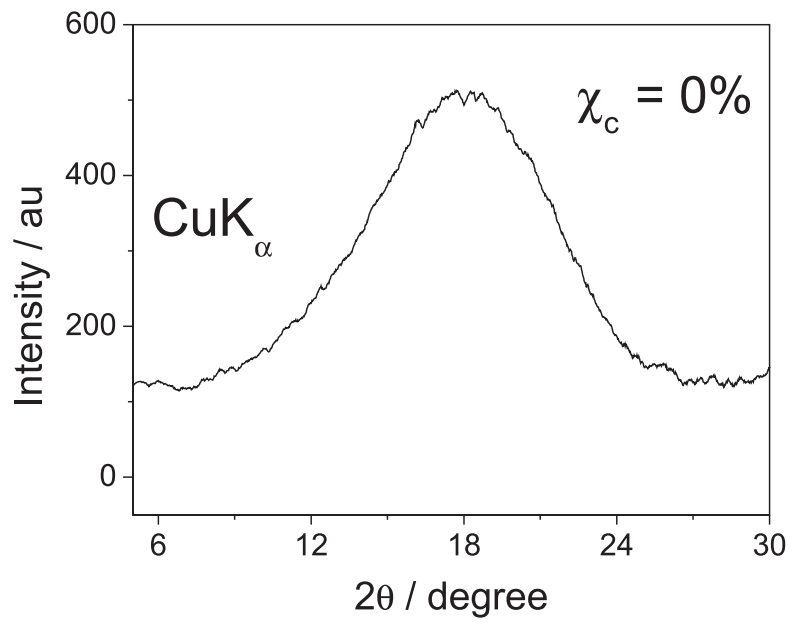

Figure S3. WAXD patterns obtained for powdered samples of $\mathbf{I}$.

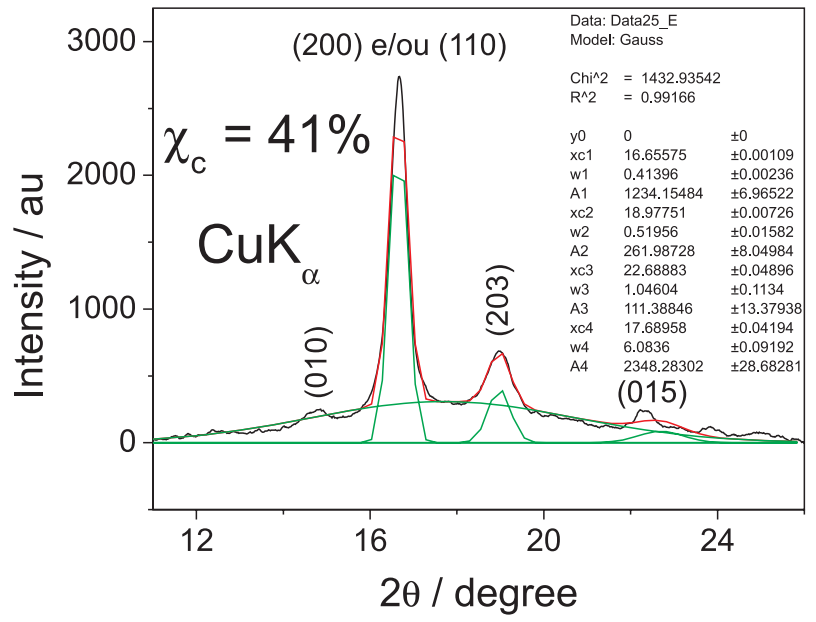

Figure S4. WAXD patterns obtained for powdered samples previously annealed ( $48 \mathrm{~h}$ at $90^{\circ} \mathrm{C}$ ) of II, with curve decompositions following Gauss function fit $\left(\mathrm{R}^{2}=0.99\right)$. "A4" corresponds to the amorphous halo areas. 


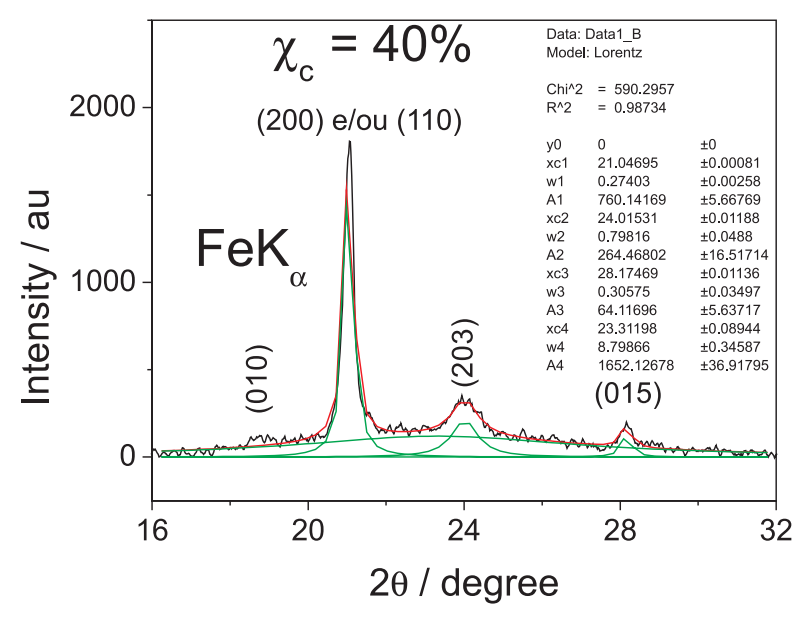

Figure S5. WAXD patterns obtained for powdered samples previously annealed $\left(48 \mathrm{~h}\right.$ at $90{ }^{\circ} \mathrm{C}$ ) of III, with curve decompositions following Lorentz function fit $\left(\mathrm{R}^{2}=0.99\right)$. "A4" corresponds to the amorphous halo areas.

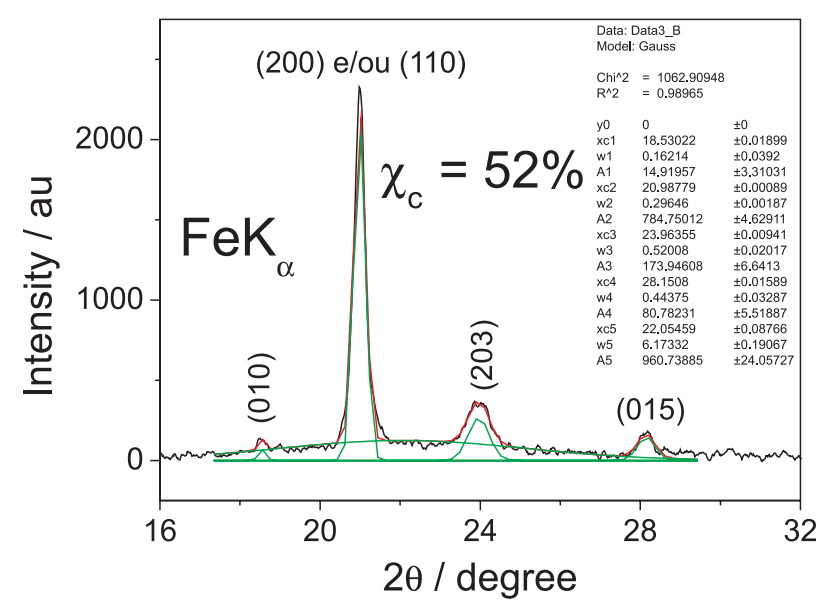

Figure S6. WAXD patterns obtained for powdered samples previously annealed $\left(48 \mathrm{~h}\right.$ at $\left.90^{\circ} \mathrm{C}\right)$ of $\mathbf{I V}$, with curve decompositions following Gauss function fit $\left(\mathrm{R}^{2}=0.99\right)$. "A5" corresponds to the amorphous halo areas. 